\title{
Hereford ırkı sığırlarda stearoyl-CoA desaturase (SCD) gen polimorfizmi
}

\section{Polymorphism of stearoyl-CoA desaturase (SCD) gene in Hereford cattle breed}

\author{
Hazniye NERGIS ${ }^{1}$ iD , Seyrani KONCAGÜL ${ }^{2}$ iD, Selahaddin KiRAZ ${ }^{3 *}$ iD \\ ${ }^{1}$ Harran Üniversitesi, Fen Bilimleri Enstitüsü, Zootekni Anabilim Dalı, Şanlıurfa \\ ${ }^{2}$ Ankara Üniversitesi, Ziraat Fakültesi, Zootekni Bölümü, Ankara \\ ${ }^{3}$ Harran Üniversitesi, Ziraat Fakültesi, Zootekni Bölümü, Şanlıurfa
}

To cite this article:

Nergis, H., Koncagül, S. \& Kiraz, S. (2019). Hereford ırkı sığırlarda stearoyl-CoA desaturase (SCD) gen polimorfizmi. Harran Tarım ve Gıda Bilimleri Dergisi, 23(2): 247-253. DOI: 10.29050 /harranziraat.487490

Address for Correspondence: Selahaddin KIRAZ e-mail:

skiraz73@gmail.com

Received Date: 27.11.2018 Accepted Date: 14.03.2019

(C) Copyright 2018 by Harran University Faculty of Agriculture. Available on-line at www.dergipark.gov.tr/harranziraat

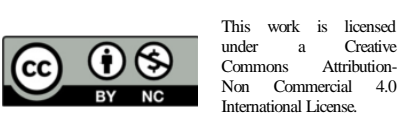

öz

$\mathrm{Bu}$ çalışmada, Hereford ırkı sığır populasyonunda Stearoyl CoA Desaturase (SCD) gen polimorfizmi belirlenmiştir. SCD geni ekson $V$ bölgesi gen dizi bilgilerine göre $A 702 G, T 762 C$ ve C878T tek nükleotid polimorfizmleri (SNP) tespit edilmiştir. A702G bölgesinde $A A, A G$ ve GG genotiplerinin frekansları sırasıyla; \%20.69, 44.83 ve 34.45, T762C bölgesinde TT, TC ve CC genotiplerinin frekansları sırasıyla; \%13.79, 62.07 ve 24.14 , C878T bölgesinde CC, CT ve TT genotiplerinin frekansları sırasıyla; $\% 44.83,31.03$ ve 24.14 olarak hesaplanmıştır. Bununla beraber, A702G bölgesinde A ve $G$ allel frekansları 0.431 ve 0.569 , T762C bölgesinde $T$ ve $C$ allel frekansları 0.448 ve 0.552 , C878T bölgesinde $C$ ve $T$ allel frekansları 0.603 ve 0.397 'dir. Ayrıca ilgili SNP'ler bakımından populasyonun Hardy-Weinberg dengesinde olmadığı belirlenmiştir $(P>0.05)$.

Anahtar Kelimeler: Hereford, Stearoyl CoA Desaturase geni, Polimorfizm

\section{ABSTRACT}

In this study, Stearoyl CoA Desaturase (SCD) gene polymorphism was determined in Hereford cattle breed. A702G, T762C and C878T single nükleotid polymorfphisms (SNPs) have been identified based on DNA sequence information of exon $V$ region in SCD gene. AA, AG and GG genotype frequencies were $20.69 \%, 44.83 \%$ and $34.45 \%$ in A702G region, and TT, TC and CC genotype frequencies were $13.79 \%, 62.07 \%$ and $24.14 \%$ T762C region, and CC, CT and TT genotype frequencies were \%44.83, 31.03 and 24.14 in C878T region, respectively. In addition, $A$ and $G$ allele frequencies were 0.431 and 0.569 in $A 702 G$ region, $T$ and $C$ allele frequencies were 0.448 and 0.552 in T762C region, and $C$ and $T$ allele frequencies were 0.603 and 0.397 in C878T region, respectively. In addition, it was found that the population was not at HardyWeinberg equilibrium in terms of related SNP genotypes.

Key Words: Hereford, Stearoyl CoA Desaturase gene, Polymorphisms

\section{Giriş}

Stearoyl-CoA Desaturase (SCD) proteini lipit metabolizmasında önemli role sahiptir. SCD enzimi (EC 1.14.19.1) yağ asidi metabolizmasında anahtar bir enzimdir ve özellikle, doymuş yağ asidi stearik asitten doymamış yağ asidi oleik asidi sentezler. Sığırlarda SCD proteini (NP_776384) 359 amino asitten oluşmaktadır ve SCD proteini SCD geni tarafından kodlanır. SCD geni sığırlarda
26. kromozom üzerinde bulunmaktadır. Sığır SCD geni 10.373 baz çifti (bç) uzunluğunda olup 4 ekzon bölge içermektedir (Gen ID: 280924, Lokasyon: 21137945-21148317). SCD gen polimorfizmi sonucu meydana gelen enzim aktivitesindeki değişikliklerin sütün içindeki diyetten bağımsız Konjuge Linoleik Asit (KLA) içeriğinin farklılığına sebep olduğu belirtilmektedir. Ayrıca SCD gen polimorfizminin 
et, süt, yağ asit bileşimine etki ettiği öne sürülmüştür (Milanesi ve ark., 2007). KLA; 18 karbon atomu ile çift bağ ihtiva eden ve esansiyel bir omega- 6 yağ asidini alan, bağlanmış hale gelen linoleik asidin fazla sayıdaki geometrik ve pozisyonel izomerlerin karışımı olarak ifade edilen ortak bir terimdir. KLA içindeki birleşmiş olan çift bağ, karbon zincirlerinde, 9 ve 10, 11 ve 12,12 ve 12 veya 11 ve 13 . pozisyonda ve birbirinden farklı cis-trans konfigürasyonlarında değişik izomerler şeklinde bulunabilir (Bölükbaşı ve ark., 2005; Köknaroğlu, 2007). Sütte KLA içeriği diyet değişiklikleri tarafından güçlü bir şekilde etkilenir: otlatmak, çim yedirmek, bitki ve balık yağından oluşan diyet eklemeleri daha yüksek KLA içeriğine sebep olmaktadır (Stockdale ve ark., 2003; Loor ve ark., 2003). Sütün KLA içeriğindeki diyetten bağımsız değişikliklerin SCD aktivitelerinden ve SCD geninin polimorfizminden kaynaklandığı belirtilmiştir (Peterson ve ark., 2002). Yakın zamandaki bir çalışmada SCD gen polimorfizmi, SCD aktivitesi ve yağlı asit bileşimleri arasında bir ilişki olduğu gösterilmiştir (Conte ve ark., 2006).

SCD'nin SCD1 ve SCD5 olmak üzere iki adet izoformu sığırlarda belirlenmiştir. SCD1 en çok mRNA miktarında, meme dokusu ve adipozda rastlanmasına karşın çok farklı dokularda da ifadelenmiştir. SCD5 ise en fazla beyin dokusunda ifadelendirilmiştir (Chung ve ark., 2000).

Sığır SCD1 geni 17088 bç büyüklüğündedir (Gen Bankası giriş no:AY241932), (Tanuguchi ve ark., 2004). SCD1 geni 5.eksonda A702G, T762C ve C878T olmak üzere 3 adet tek nükleotid polimorfizmi'ne (SNP) rastlanmıştır. SCD1 geni ile sığırlarda sırt ve iskelet kasında mermerleşme derecesi, tekli doymamış yağ asidi ve KLA miktarları arasında pozitif bir ilişki olduğu bildirilmektedir (Tanuguchi ve ark., 2004; Matsuhashi ve ark., 2011). Sığırlarda süt ve et yağ kalitesini genetik olarak geliştirmede SCD lokusunun çok önemli bir potansiyele sahip olduğu açıklanmıştır (Macciota ve ark., 2008).

Insanlar için daha sağlıklı et ve süt ürünlerinin elde edilmesinde yağ asidi içeriklerinin önemli olduğu bilinmektedir. Yapılan bilimsel çalışmalarda yağ asidi içeriğinin insan sağlığı için olumlu olarak düzenlenmesinde, SCD geni polimorfizminin potansiyelinin yüksek olduğu vurgulanmaktadır. Bu çalışmada, Hereford ırkı sığılarda SCD gen polimorfizminin belirlenmesi amaçlanmıştır.

\section{Materyal ve Metot}

Araştırmanın DNA izolasyonu için, gerekli doku materyali Şanlıurfa-Merkez bölgede faaliyet gösteren özel bir besi işletmesinde, 155 günlük besiye tabii tutulmuş ve besi sonrası ilgili işletme bünyesindeki kombinede kesimleri gerçekleştirilmiş 6-9 aylık yaştaki Hereford ırkı kastre edilmiş 29 baş sığırdan alınmış ve bunlara ait veriler araştırmanın materyalini oluşturmuştur. Doku örnekleri, doğrudan temas ve kontaminasyonu önlemek için lateks eldivenlerle karkasın boyun kısmından alınmıştır. Her bir hayvan için toplanan örnekler poşetlere konarak, etiketlendirilip laboratuvara ulaştırılıncaya kadar muhafaza edilmiştir. Örnek etiketi üzerine, hayvana ait bilgiler yazılmıştır.

\section{DNA izolasyonu}

Sığırlardan doku genomik DNA izolasyon kiti (NucleoSpin ${ }^{\circledR}$ Tissue MACHEREY-NAGEL) kullanılarak genomik DNA izole edilmiştir. İzole edilen DNA örneklerinin görüntülenmesinde \%1'lik agaroz jel kullanılmıştır.

\section{Moleküler analizler}

Sığır SCD geni ekson 5 bölgesinde 552 bç'lik bir fragmanı amplifiye etmek için tasarlanmış (Milanesi ve ark., 2008) primer çifti kullanılmıştır (GenBank Erişim No. AY241932).

Ileri (foward) Primer: 5CAGAAAATTTCCTTGCCCATT-3

Geri (reverse) Primer: 5-

TGTTGCTTAACTTTCAAGGGTTT-3 
Çizelge 1. Bos taurus stearoyl-CoA desaturase (SCD) geni, ekzon 5 sekansı

Table 1. Bos taurus stearoyl-COA desaturase (SCD) gene, exon 5 sequence

TAAGATCCCCTTGTGCCACCTGGTGTGGCCCAAAAAAAAAATAAAAGATTGACTTAAACATAGATTCTGCGAAGAGCACTGCTGA AAGAGAAAGGAAGCCCAAAGGCAGAACAGAAAAACCCGGGAAGGAGAACTCAGTCTGTAATTTGGACCCTGTCTATTTCCCTGAA GTAGTAAAAGAGAGCAATGGATTTAGAGTCAGGAGATGAAACATTCCAGTCCTTGCTCCACCACTTCCTGGTAGTGTGACCCTAG AAAAGTCATTTAACCCCTCATTACCTCATCTCAGAAGTATGATAATAACACTGTATTCT

TTGTTCTGTTGCCTGCCACACTGTGCTCTCAGTGTAGAAAGGGACAGCCCCGCCCTGTGAGAGTGGAAAATCAGGTAGGTCTCAG CGTCCCCTCTCCACTCACTGAGCCTGTGATCTCTCAATGCAGGTACTACAAACCTGGTGTCCTGTTGTTGTGCTTCATCCTGCCC ACACTCGTGCCATGGTATCTGTGGGATGAAACGTTTCAAAACAGCCTGTTTTTTGCCACCTTATTCCGTTATGCCCTTGGGCTCA ACGTCACCTGGCTGGTGAATAGTGCTGCCCATATGTATGGATACCGCCCTTATGACAAGACCATCAACCCCCGAGAGAATATTCT GGTTTCCCTGGGAGCTGTGGGTAAGTCAGCAGTCCACAGCAAGACCACGTCTAGTGGTCTGCTGCTTAGGGTATTAGGTTACGTG CCAGAAAAACTAGATTTACCTGTTTTATGACCCCTCTCCGTATGTCATTCCACTATAAAACTAAGGGACAGTATTAGA

TGAAAGTTAAGCAACAAGTCCTATGTAAAGAGAAAAGGGTGAAAAATGACAATGCCTTTAATTCCAGGTTTAAGAGCAAGCCACA AATGCTATGTATGATGAACCCCTTTGGGCTGTTCTCTTCCCAGTCATCTCTGATCTGGGTGGTAGTCTTGCTTGGGGCAGGGAAT GCATAAATAGAAGAGTAGGGTCATCTGGGTGGCCAGAAAGCCTAGTATTTTACATTTAGTTGTGATATACAGAACAAATACTTGT CATTTAACTCACTAAGCTTCTCTTTTATCACCTTCCTGTATTCAGAGGGGCAATATTTGAAGTGTATTACATGCCTTACTA

Sığır SCD geni ekson 5 bölgesinin polimeraz zincir reaksiyonu (PZR) tekniği ile çoğaltılmasında kullanılacak PZR karışımı Çizelge 2'de gösterilmiştir. $\mathrm{Bu}$ bileşenlerin tümü belirtilen miktarlarda kuru buz üzerindeki 0.2 ml'lik PZR ependorf tüpleri içerisinde hazırlandıktan sonra, PZR şartları önceden programlanmış PZR cihazına yerleştirilmiştir. Çalışılan gen bölgesinin polimeraz zincir reaksiyonu tekniği ile çoğaltılmasında kullanılacak PZR amplifikasyon şartları Çizelge 3'te verilmiştir. PZR çalışmaları gradient özelliğe sahip Boeco thermocycler (Germany) marka cihazda yapılmıştır.

Çizelge 2. PZR karışımı

Table 2. PCR mixture

\begin{tabular}{|c|c|c|}
\hline Bileşenler & Konsantrasyon & Miktar \\
\hline Componants & Concentration & Quantity \\
\hline Kalıp DNA & $20-30 \mathrm{ng} \mu \mathrm{l}^{-1}$ & $1.0 \mu \mathrm{l}$ \\
\hline PCR Buffer & $10 x$ & $4.0 \mu \mathrm{l}$ \\
\hline İleri Primer & $10 \mathrm{pmol}_{\mu \mathrm{I}^{-1}}$ & $1.0 \mu \mathrm{l}$ \\
\hline Geri Primer & $10 \mathrm{pmol} \mu \mathrm{l}^{-1}$ & $1.0 \mu \mathrm{l}$ \\
\hline dNTP mix & $1.0 \mathrm{nM}$ & $1.0 \mu \mathrm{l}$ \\
\hline Taq DNA polimeraz & $\left.5 U \mu\right|^{-1}$ & $0.5 \mu \mathrm{l}$ \\
\hline $\mathrm{dH}_{2} \mathrm{O}$ & & $32.0 \mu \mathrm{l}$ \\
\hline Toplam & & $40.0 \mu \mathrm{l}$ \\
\hline
\end{tabular}

Çizelge 3. PZR amplifikasyon şartları

Table 3. PCR amplification conditions

\begin{tabular}{|c|c|c|c|}
\hline Döngü işlemi & Sicaklık $\left({ }^{\circ} \mathrm{C}\right)$ & Döngü sayısı & Süre \\
\hline Cycle process & Temparature & Number of cycle & Time \\
\hline Ön denaturasyon & 95 & 1 & 4 dakika \\
\hline Denatürasyon & 94 & 1 & 30 saniye \\
\hline Yapışma $\left(T_{m}\right)$ & 55 & 30 & 30 saniye \\
\hline Sentez & 72 & & 1 dakika \\
\hline Son uzama & 72 & 1 & 10 dakika \\
\hline Bekleme & 4 & $\infty$ & $\infty$ \\
\hline
\end{tabular}

PZR Programı

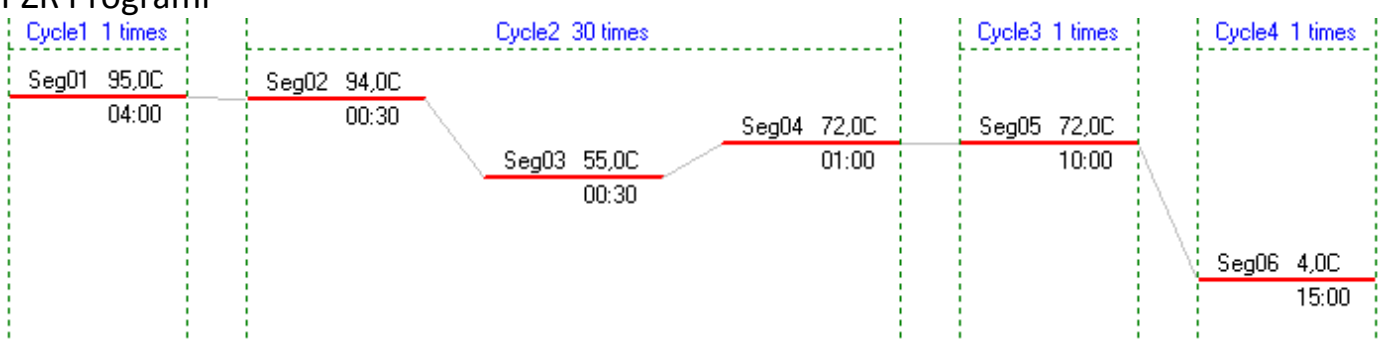


Çoğaltılan PZR ürünlerinin görüntülenmesinde $\% 1,5^{\prime}$ luk agaroz jel kullanılmıştır $(1,5 \mathrm{~g}$ agarose/100 ml 1XTBE). PZR jellerinin koşturulmasında marker olarak 100 bç'lik ladder (Fermentas) kullanılmıştır.

Sığır SCD geni ekson 5 bölgesinin PZR amlifikasyonu gerçekleşmiş örnekler gen dizileme için seçilerek ileri (F) ve geri (R) zincir olmak üzere örnekler $50 \mu \mathrm{l}$ olarak (25 $\mu \mathrm{l}$ PZR ürünü $+25 \mu \mathrm{l}$ $\mathrm{ddH}_{2} \mathrm{O}$ ) hazırlanmıştır. Dizileme işlemi hizmet alımı şeklinde yapılmıştır.

\section{Gen dizilerin değerlendirilmesi}

1) PZR ürünlerinin ileri $(F)$ ve geri $(R)$ zincir kromatoğramlarını içeren dosyalar (h01_F.ab1 ve h01_R.ab1) Finch TV 1.4 paket programında açılarak görüntülenmiştir. Burada kromatoğramdaki pikler incelenerek ve pik sinyalleri belirgin ve kaliteli olan dizi örnekleri değerlendirilmeye alınmıştır.

2) Görüntülenen h01_F.ab1 dosyasından dizi bilgileri FASTA formatta bir not defteri dosyasına (h01.txt) transfer edilecektir. h01_R.ab1 dosyasındaki görüntü "reverse komplementer"e çevrilerek benzer şekilde dizi bilgileri FASTA formatta not defteri dosyasına aktarılmıştır. h01.txt dosyasına ilgili gene ait referans dizi bilgileri de eklenerek h01 örneği için veri dosyası oluşturulmuştur.

3) Veri dosyası (h01.txt) kullanılarak Clustal W programı ile çoklu dizi hizalama (multiple sequence alignment) yapılmıştır. Burada amaç hem ileri hem geri dizi uyumunu görmek hem de referans dizi ile de karşılaştırarak konsensüs sağlanan dizilerin (Clustal consensus) belirlenmesini sağlamaktır. Ayrıca referans dizi temel alınarak ileri ve geri zincirle birlikte konsensüs bölgelerde, tespit edilen nükleotid yer değişimleri (transisyon/transversiyon) veya indel (insersiyon ve delesyon) bölgeler işaretlenerek h01 örneğimiz için ilk aşama dizi bilgisi elde edilmiştir.
4) Benzer aşamalar diğer tüm örnekler içinde yapılmıştır. Tüm örnekler için elde edilen ilk aşama dizilerde tekrar çoklu dizi hizalama yapılmış ve tüm diziler için ortak konsensüs bulunan bölgeler belirlenmiştir.

5) Dizi setlerini içeren dosyalar (*.txt), genetik analizlerin yapılması için ilgili paket programlarda kullanılmak üzere değişik formatlara (FASTA, NEXUS, MEGA) çevrilmiştir.

\section{SCD genotiplerinin belirlenmesi}

Örneklere ait gen dizileri bilgileri kullanılarak genotiplendirme yapılmıştır. Genotiplendirme sonrası ilgili lokus bakımından gen ve genotip frekansları belirlenmiştir. Gen ve genotip frekansları hesaplanmakla birlikte, ayrıca populasyonun Hardy-Weingberg dengesinde olup olmadığını kontrol etmek üzere Ki-Kare ( $\chi 2)$ testi yapılmıştır (Yeh ve ark., 1997). Gen ve genotip frekanslarının hesaplanması ile $\chi 2$ analizleri için PopGene 3.2 paket programı kullanılmıştır.

\section{Araştırma Bulguları ve Tartışma}

\section{SCD Gen Polimorfizmi}

Tüm örneklerde SCD geni ekzon 5 bölgesini içeren 552 bç uzunluğunda PZR ürünleri elde edilmiştir. SCD geninde polimorfizm DNA dizi bilgileri kullanılarak belirlenmiştir. illgili gen bölgesinde A702G, T762C ve C878T SNP'leri tespit edilmiştir. Bu SNP'lere ait allel ve genotip frekansları Çizelge 4'te verilmiştir. Bu çalışmada, SCD geni ekzon 5 bölgesini içeren 552 bç uzunluğunda PZR ürünleri elde edilmiştir. SCD geninde polimorfizm DNA dizi bilgileri kullanılarak belirlenmiştir. SCD geni ekson 5 bölgesi gen dizi bilgilerine göre $A 702 G, T 762 C$ ve C878T SNP tespit edilmiştir. A702G bölgesinde $A A, A G$ ve $G G$ genotiplerinin frekansları sırasıyla; \%20.69, 44.83 ve 34.45, T762C bölgesinde TT, TC ve CC genotiplerinin frekansları ise sırasıyla; \%13.79, 62.07 ve 24.14, C878T bölgesinde CC, CT ve TT genotiplerinin frekansları sırasıyla; \%44.83, 31.03 ve 24.14 olarak hesaplanmıştır. Bununla beraber, A702G bölgesinde $A$ ve $G$ allel frekansları 0.431 ve 
0.569 , T762C bölgesinde $T$ ve $C$ allel frekansları 0.448 ve 0.552 , C878T bölgesinde de $C$ ve $T$ allel frekansları 0.603 ve 0.397 olarak hesaplanmıştır. Ayrıca ilgili SNP'ler bakımından populasyonun
Hardy-Weinberg

dengesinde

olmadığı belirlenmiştir. Yapılan çalışmada, allel ve genotip frekansları bakımından populasyonun HardyWeinberg dengesinde olmadığı görülmüştür.

Çizelge 4. SCD geni genotip ve allel frekansları

Table 4. Genotype and allele frequencies of SCD gene

\begin{tabular}{|c|c|c|c|c|c|c|c|}
\hline SNP & & \multicolumn{3}{|c|}{$\begin{array}{l}\text { Genotip frekansları } \\
\text { Genotype frequencies }\end{array}$} & \multicolumn{2}{|c|}{$\begin{array}{c}\text { Allel frekansları } \\
\text { allele frequencies } \\
\%\end{array}$} & \multirow[t]{2}{*}{$\begin{array}{c}\text { HWE } \\
\text { p-değeri } \\
p \text {-value }\end{array}$} \\
\hline \multirow[t]{6}{*}{ A702G } & Gözlenen & $A A$ & $A G$ & GG & \multirow{6}{*}{$\begin{array}{c}A \\
0.431\end{array}$} & \multirow{6}{*}{$\begin{array}{c}G \\
0.569\end{array}$} & \\
\hline & $\mathrm{n}$ & 6 & 13 & 10 & & & \multirow{5}{*}{0.6430} \\
\hline & $\%$ & 20.69 & 44.83 & 34.48 & & & \\
\hline & Beklenen & & & & & & \\
\hline & $\mathrm{n}$ & 5.39 & 14.22 & 9.39 & & & \\
\hline & $\%$ & 18.58 & 49.05 & 32.37 & & & \\
\hline \multirow[t]{6}{*}{ T762C } & Gözlenen & TT & TC & $\mathrm{CC}$ & \multirow{6}{*}{$\begin{array}{c}\mathrm{T} \\
0.448\end{array}$} & \multirow{6}{*}{$\begin{array}{c}C \\
0.552\end{array}$} & \multirow{6}{*}{0.1700} \\
\hline & $\mathrm{n}$ & 4 & 18 & 7 & & & \\
\hline & $\%$ & 13.79 & 62.07 & 24.14 & & & \\
\hline & Beklenen & & & & & & \\
\hline & $\mathrm{n}$ & 5.83 & 14.34 & 8.83 & & & \\
\hline & $\%$ & 20.10 & 49.46 & 30.44 & & & \\
\hline \multirow[t]{6}{*}{ C878T } & Gözlenen & $\mathrm{CC}$ & CT & TT & \multirow{6}{*}{$\begin{array}{c}C \\
0.603\end{array}$} & \multirow{6}{*}{$\begin{array}{c}\mathrm{T} \\
0.397\end{array}$} & \multirow{6}{*}{0.0583} \\
\hline & $\mathrm{n}$ & 13 & 9 & 7 & & & \\
\hline & $\%$ & 44.83 & 31.03 & 24.14 & & & \\
\hline & Beklenen & & & & & & \\
\hline & $\mathrm{n}$ & 10.56 & 13.88 & 4.56 & & & \\
\hline & $\%$ & 36.41 & 47.86 & 15.73 & & & \\
\hline
\end{tabular}

HWE: Hardy-Weinberg dengesi
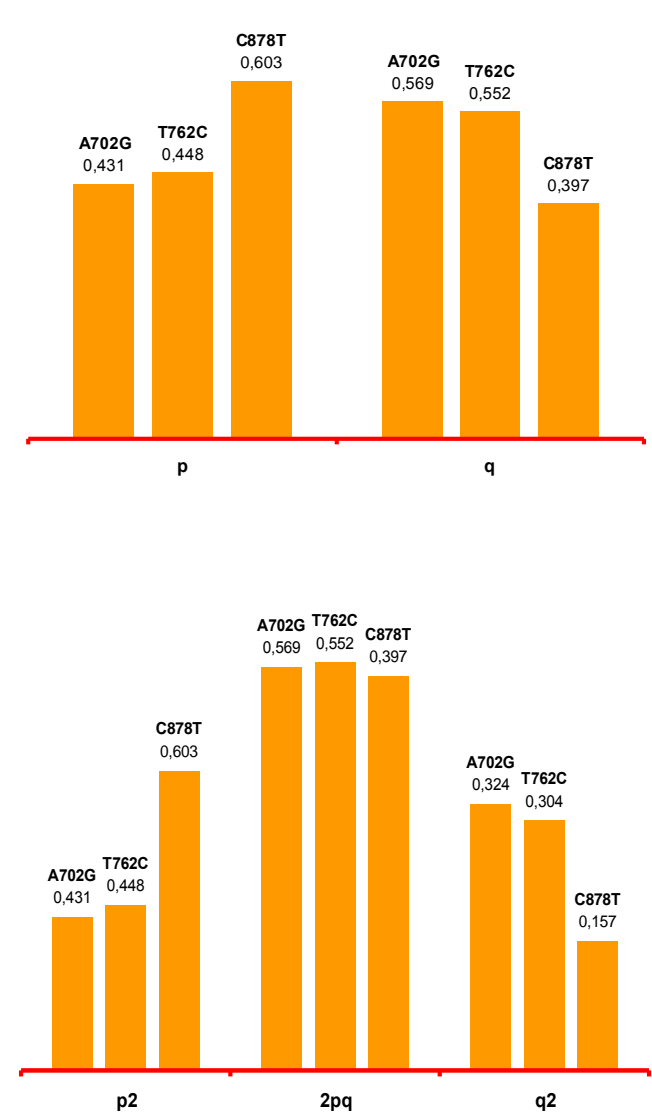

Şekil 1. SCD geni A702G, T762C ve C878T SNP allel ve genotip frekansları

Figure 1. Allele and Genotypefrequencies of A702G, T762C and C878T SNPs in SCD gene
Holstein, Jersey ve İsviçre Esmeri ırkı sığırlarda SCD bakımından 8 adet tek nükleotid polimorfizmi (SNP) belirlenmiştir. Bunlardan 3 adeti 5. eksonda ve 5 adeti ise 3'ucu kodlama yapmayan bölgede yer almaktadır. 5. eksonda yer alan 3 SNP sirasıyla, A702G, T762C ve C878T'dir (Tanuguchi ve ark., 2004). C878T (pozisyon 10329) da yer alan SNP Alanin (293Ala) ve Valin varyantı (293 Val) olmak üzere iki adet protein varyantının oluşmasına neden olur. Bu aminoasit değişimi (Ala293Val) enzimin katalitik aktivitesini de değiştirmektedir (Tanuguchi ve ark., 2004).

Kanada Jersey ırkı sığırlarda Alanin varyantı doymuş C10, C12, C14'ün doymamış C10:1, C12:1 ve C14:1'e dönüşümü olumlu yönde etkilemesine rağmen C16:1, C18:1, tekli doymamış yağ asitleri, KLA ve çoklu doymamış yağ asitleri üzerine etkisinin olmadığını ifade etmişlerdir (Kgwatalala ve ark., 2009). Bunun sonucunda araştırmacılar SCD genini her ne kadar total doymamışlık indeksine etkisi olmasa da tek yağ asidi indeksine etkisinden dolayı insanlar için sağlıklı ürünleri elde edilmesi ve süt yağ asidi kompozisyonunun geliştirilmesinde çok önemli bir etkiye sahip olduğunu belirtmişlerdir (Kgwatalala ve ark., 2009). Aynı çalışmada A alleli ile süt proteini miktarı ve süt verimi arasında olumlu bir ilişkinin 
olduğunu belirtmişlerdir. Diğertaraftan, Macciota ve ark. (2008)'da ittalya Holstein sığır ırkında yaptıkları çalışmada AA genotipine sahip hayvanların VV genotipli hayvanlardan daha düşük süt protein miktarına ve süt verimine sahip olduklarını ileri sürmüşlerdir. Bu çalışmalar SCD geninin süt özelliklerine etki ettiği, ama SCD geni allellerinin etkilerinin nasıl olduğu tartışmalı bir duruma getirmiştir. SCD geni A263V polimorfizminin protein içeriği ve hem süt hem de karkas yağ asidi üzerine çok önemli derecede etkilerinin bulunduğunu bu sebepledir ki et yağ ve süt asidi kompozisyonunu farklılaştırarak insanlar için daha sağlıklı ürünlerin elde edilmesinde potansiyeli olduğu ileri sürülmektedir (Tanuguchi ve ark., 2004; Macciota ve ark., 2008; Matsuhashi ve ark., 2011). SCD geni, sığırlarda et ve süt özelliklerinin moleküler ıslahı açısından genetik ilerlemenin daha hızlı olması yanında, marker destekli seleksiyon (MAS = Marker Asisted Selection) için potansiyel oluşturacağı vurgulanmıştır (Elmas ve ark., 2015).

\section{Sonuç}

Sonuç olarak, Hereford sığır ırkında SCD geni ekson 5 bölgesi gen dizi bilgilerine göre A702G, T762C ve C878T tek nükleotid polimorfizmleri (SNP) tespit edilmiştir. SCD geni sığırlarda et ve süt özelliklerini etkileyen aday bir gen olarak seçilebilir. SCD geni üzerinde birçok tek nükleotid polimorfizm (SNP) tanımlanmıştır. Bununla beraber, SCD genindeki SNP'ler ile et ve süt özellikleri arasında bağlantının bulunabilme potansiyeli yüksektir. Bu durum ıslah programlarında hayvansal ürünlerin daha verimli ve ekonomik olarak elde edilmesine olanak sağlayacaktır.

\section{Ekler}

Bu makale, Doç. Dr Seyrani KONCAGÜL ve Dr. Öğr. Üyesi Selahaddin KíRAZ danışmanlığında Hazniye NERGiS'in hazırladığı yüksek lisans tezinden özetlenmiştir. Bu çalışma HÜBAK tarafından desteklenmiştir (Proje No: 13054).

\section{Kaynaklar}

Bölükbaşı, C., Erhan, M.K., \& Çelebi, Ş. (2005). The effects of dietary conjugated linoleic acid (CLA), sunflower oil and soybean oil on fatty acid composition of yolk and egg quality in laying hen. Journal of Food Technology, 3(3), 427-429.

Chung, M., Ha, S., Jeong, S., Bok, J., Che, K., Baik, M., \& Choi, Y. (2000). Cloning and characterization of bovine Stearoyl COA desaturase cDNA from adipose tissues. Bioscience, Biotechnology and Biochemistry, 64, 1526-1530.

Conte, G., Mele, M., Castiglinoni, B., Serra, A., Viva, M., Chessa, S., Pagnacco, G., \& Secchiari, P. (2006). Relationship between bovine SCD polymorphism locus and mammary gland desaturation activity. In: Proceedings of the 8th World congress on genetics applied to livestock production (pp. 22-37). Belo Horizonte, Minas Gerais, Brazil,13-18 August.

Elmas, H., Koncagül, S., \& Kiraz, S. (2015). Sığırlarda SCD (stearoyl-coa desaturase) geni. GAP VII. Tarım Kongresi Bildiri Kitabı, 28 Nisan -01 Mayıs. HRÜ. Şanlıurfa.

Kgwatalala, P.M., Ibeagha-Awemu, E.M., Mustafa, A.F., \& Zhao, X. (2009). Influence of Stearoyl coenzyme a desaturase 1 genotype and stage of lactation on fatty acid composition jersey cows. Journal of Dairy Science, 92, 1220-1228.

Köknaroğlu, H. (2007). Beslemenin sığır eti konjuge linoleik asit miktarına etkisi. Hayvansal Üretim, 48(1), 1-7.

Loor, J.J., Lin, X.B., \& Herbein, J.H. (2003). Effects of dietary cis-9, trans-11-18:2, trans-10, cis-1218:2, or vaccenic acid (trans-11-18:1) during lactation on body composition, tissue fatty acid profiles, and litter growth in mice. British Journal of Nutrition, 90, 1039-1048.

Macciota, N.P.P., Mele, M., Conte, G., Serra, A., Cassandro, M., Dal Zotto, R., Borlino, A.C., Pagnacco, G., \& Secchiari, P. (2008). Association between a polymorphism at the Stearoyl-CoA desaturase locus and milk production traits in Italian Holsteins. Journal of Dairy Science, 91, 3184-3189.

Matsuhashi, T., Maruyama, S., Uemoto, Y., Kobayashi, N., Manen, H., Abe, T., Sakaguch, S., \& Kobayashi, E. (2011). Effects of bovine fatty acid synthase, Stearoyl coenzyme a desaturase, sterol regulatory element-binding protein 1 , and growth hormone gene polymorphisms on fatty acid composition and carcass traits in Japanese black cattle. Journal of Animal Science, 89, 1222.

Milanesi, E., Nicoloso, L., \& Crepaldi, P. (2007). Stearoyl CoA Desaturase (SCD) gene polymorphisms in Italian cattle breeds. sezione di zootecnica agraria, dipartimento di scienze animali, Universita Delgi Studi di Milano, Milamo, Italy.

Milanesi, E., Nicoloso, L., \& Crepaldi, P. (2008). Stearoyl CoA desaturase (SCD) gene 
polymorphisms in Italian cattle breeds. Journal of Animal Breeding and Genetics, 125(1), 63-67.

Peterson, D.G., Kelsey, J.A., \& Bauman, D.E. (2002). Analysis of variation in cis-9, trans-11 conjugated linoleic acid (CLA) in milk fat of dairy cows. Journal Dairy Science, 85: 2164-2172.

Stockdale, C.R., Walker, G.P., Wales, W.J., Dalley, D.E., Bırkett, A., Shen, Z., \& Doyle, P.T. (2003). Influence of pasture and concentrates in the diet of grazing dairy cows on the fatty acid composition of milk. Journal of Dairy Research, 70, 267-276.
Tanuguchi, M., Utsugi, T., Oyama, K., Manen, H., Kobayashi, M., Tanabe, Y., Ogino, A \& Tsuji, S. (2004). Genotype of Stearoly Coenzyme-A Desaturase is Associated with Fatty Acid Composition in Japanese Black Cattle. Mammalian Genome, 14, 142-150.

Yeh, F.C., Yang, R.C., Boyle, T.B.J., \& Mao, J.X. (1997). Theuser-Friendly Share Ware for Population Genetic Analysis. University of Alberta, Canada. 